SHORT REPORT

\title{
Cold blast furnace syndrome: a new source of toxic inhalation by nitrogen oxides
}

I Tague, P Llewellin, K Burton, R Buchan, D H Yates

Occup Environ Med 2004;61:461-463. doi: 10.1136/oem.2002.005686

\begin{abstract}
Aim: To describe a new toxic inhalation syndrome in blast furnace workers.

Methods: Fourteen workers developed acute respiratory symptoms shortly after exposure to "air blast" from blast furnace tuyeres. These included chest tightness, dyspnoea, rigors, and diaphoresis. Chest radiographs showed pulmonary infiltrates, and lung function a restrictive abnormality. This report includes a description of clinical features of the affected workers and elucidation of the probable cause of the outbreak.

Results: Clinical features and occupational hygiene measurements suggested the most likely cause was inhalation of nitrogen oxides at high pressure and temperature. While the task could not be eliminated, engineering controls were implemented to control the hazard. No further cases have occurred.

Conclusions: "Cold blast furnace syndrome" represents a previously undescribed hazard of blast furnace work, probably due to inhalation of nitrogen oxides. It should be considered in the differential diagnosis of acute toxic inhalational injuries in blast furnace workers.
\end{abstract}

M odern steel manufacture involves the use of a blast furnace, where raw materials are reduced to molten iron and slag. Materials descend through a coke bed and are tapped at the base of the vessel. Hot, enriched "air blast" is injected through a series of tuyeres (air inlets) in the base of the furnace, where reduction of iron oxide to molten iron occurs. Occasionally, factors (for example, a power cut) may temporarily stop the supply of air blast, allowing cooling of the iron and slag. This is referred to as a "cold furnace". In such circumstances, workers will plug most of the tuyeres with refractory material, then resume operation on the remaining tuyeres to restore heat to the material entering the hearth. As the furnace heats up, workers will unblock the tuyeres without stopping the furnace.

Unblocking tuyeres is a difficult job requiring at least six men and personal protective equipment. A "gland" is attached to the area delivering hot air to the tuyere, and a rock drill with a $3 \mathrm{~m}$ steel drill part is inserted through the "gland" and forcefully pushed towards the opening of the tuyere into the blast furnace. Because interruption of function of the blast furnace is unusual, unblocking of tuyeres in a cold furnace is an uncommon, but periodic event.

\section{CASE DESCRIPTIONS}

In three separate incidents of "cold furnace", 14 of a total of 18 workers exposed to blast furnace fumes during tuyere unblocking noticed identical symptoms. Shortly after exposure, they developed marked chest tightness and cough precipitated by deep breathing. Fifteen to 30 minutes later, several men developed shivers, a sensation of cold, and exertional dyspnoea. One man had a single episode of haemoptysis. Symptoms took approximately one week to resolve. After the first incident, three men were sent to hospital (table 1). All recovered within two weeks, but one with pre-existing asthma developed an exacerbation. Symptoms were improved by oxygen and supportive measures. Further treatment was only required in one case (the asthmatic). Workers in the later incidents were less severely affected, possibly because of changes made to the process, and did not require hospitalisation.

All workers were fit, only one having a history of previous respiratory disease. Interestingly, two of the workers could recall having had identical symptoms eight years previously, after unblocking tuyeres. This was confirmed in one case by an entry in the medical records, which reported that he had been "coughing and unable to take deep breaths". Several workers had previously experienced zinc fume fever and carbon monoxide poisoning, but said their symptoms were different.

Chest radiographs in four men showed bilateral lower zone infiltrates suggestive of pulmonary oedema. Changes resolved within 24 hours. Lung function showed significant restriction, with improvement to baseline within one month. Repeat assessments one and two years later were within normal limits (except for pre-existing disease).

\section{OCCUPATIONAL HYGIENE MEASUREMENTS}

Personal and stationary monitoring was conducted when opening tuyeres. Inspirable and respirable dusts were analysed for iron, zinc, calcium, aluminium, cadmium, arsenic, and vanadium using inductively coupled plasma atomic emission spectrophotometry. Concentrations were low or not detected. Respirable dust was analysed for quartz with an infrared spectrometer, but low concentrations were present. Benzene soluble fraction of total particulate matter (BSF), a measure of the fine particulate or fume, failed to confirm significant hydrocarbons. Monitoring for hydrogen cyanide, sulphur dioxide, hydrogen sulphide, and carbon monoxide using a GEM personal monitor showed levels well below the Worksafe Australia standards. ${ }^{1}$ Monitoring for organic contaminants by gas chromatography showed low levels.

Results of initial monitoring thus did not identify the likely cause. Careful consideration of clinical features suggested that symptoms might be due to exposure to nitrogen oxides. Additional stationary monitoring was therefore undertaken to establish if these were present in the blast. Continuous sampling of the gas was conducted through a device attached to the tuyere and passed through a cooling coil and pressure diverter into the analysing instrument. Sampling was performed during normal operation of the blast furnace over a period of 43 minutes after a period when the wind volume was reduced. High peaks of 
Main messages

- "Cold blast furnace syndrome" results in acute dyspnoea, chest tightness, and pulmonary oedema.

- This is probably due to exposure to nitrogen oxides $\left(\mathrm{NO}_{\mathrm{x}}\right)$, which may occur during the recovery process of a "cold blast furnace".

nitrogen oxides occurred directly after a stove change (73 and $78 \mathrm{ppm}$ ), with the second peak when the wind volume was reduced. Nitrogen dioxide was not detected during the monitoring period.

\section{DISCUSSION}

This report identifies a previously undescribed hazard of work in blast furnaces, which we have called "cold blast furnace syndrome". Inhalation of toxic fumes produced a highly characteristic syndrome in 14 of 18 workers. Given the similarity of descriptions from affected workers employed in different blast furnaces, the same agent is likely to have been inhaled on each occasion. The differences in the severity of the response between workers presumably reflect differences in dose produced by variations in proximity to the blast, differing process conditions, individual variations in respiratory rate and respiratory protection, and ongoing attempted engineering solutions.

"Air blast" from the furnace is a complex mixture of different gases containing carbon monoxide, sulphur dioxide, ozone, and heavy metals. Sampling showed that none of these were above exposure standards, so another agent was presumed responsible.

It seemed likely that levels of the toxic agent inhaled were high, in view of the systemic symptoms experienced by the workers. It was likely that the toxic agent(s) was relatively water insoluble, as soluble agents tend to provoke irritation and inflammation of the proximal respiratory mucosa, and in these cases alveolar oedema was observed as well as an acute laryngo-tracheitis. Clinical features suggested exposure to high levels of oxides of nitrogen.

Nitrogen oxides $\left(\mathrm{NO}_{\mathrm{x}}\right)$ occur in the "air blast" in high levels (up to $1000 \mathrm{ppm}$ ), and are generated particularly under conditions of cooling. ${ }^{2} \mathrm{NO}_{\mathrm{x}}$ and particularly nitric oxide (NO) have been implicated in furnace cracking, which contributes to blast furnace dysfunction. ${ }^{3}$ We measured nitric oxide in the "air blast" in levels well into the toxic range. While results recorded were related to conditions at the time of monitoring and may not necessarily correlate exactly with conditions at the time of the incidents, process records indicated that the blast parameters and the stove conditions were likely to have been similar.

Poisoning by $\mathrm{NO}_{\mathrm{x}}$ has been previously described in relation to silo-fillers' disease, ${ }^{4}$ anaesthetic gases, ${ }^{5}$ and in spectators of ice-hockey games. ${ }^{6} \mathrm{NO}$ and nitrogen dioxide $\left(\mathrm{NO}_{2}\right)$ are invariably found together, concentrations depending on relative concentrations of oxygen and NO. With inhalation of high concentrations of $\mathrm{NO}_{\mathrm{x}}$, acute pulmonary oedema is well recognised, as is a sensation of chest pain, cough, shortness of breath, and haemoptysis. ${ }^{6}$ Usually, such symptoms resolve fairly quickly, as $\mathrm{NO}_{\mathrm{x}}$ are very reactive gases and are rapidly absorbed by the bloodstream.

The Worksafe Australia TWA Exposure Standard is 3 ppm for $\mathrm{NO}_{2}$ and $25 \mathrm{ppm}$ for $\mathrm{NO}$, with a short term exposure limit (STEL) of 5 ppm. Exposure to $>50 \mathrm{ppm}$ of $\mathrm{NO}_{2}$ may cause chest pain and pulmonary oedema, ${ }^{7}$ with an estimated 1 hour $\mathrm{LD}_{50}$ for humans of $174 \mathrm{ppm}^{8}{ }^{9}$ Levels required for
Policy implications

- Occupational physicians should be aware of the hazard regarding nitrogen oxides $\left(\mathrm{NO}_{\mathbf{x}}\right)$ in blast furnace operations.

- Occupational hygiene surveillance should include measurement of $\mathrm{NO}_{x}$.

- Engineering controls may be required to minimise exposure to blast furnace gases.

- Regular worker surveillance (including lung function) is recommended.

NO toxicity are incompletely understood, and clinical effects may be difficult to separate from $\mathrm{NO}_{2}$ toxicity. Clutton-Brock reported a case of fatal pulmonary oedema in a 39 year old woman who died after exposure to $\mathrm{NO}_{\mathrm{x}}$ from a contaminated nitrous oxide cylinder during anaesthesia. The presumed concentration was thought to be approximately 10000 ppm. ${ }^{5}$ Inhaled NO is currently used in ICU settings in the range of 10-20 ppm. ${ }^{10}$

Although the samples were not collected in the breathing zone of workers and hence cannot be directly compared to occupational exposure standards, stationary sampling confirmed high concentrations of nitrogen oxides were present in the tuyere gas, at 73 and $78 \mathrm{ppm}$. Following the incidents, the "gland" was altered, and the standard operating procedure for opening tuyeres revised. On several subsequent occasions the procedure has been repeated without incident.

Toxic inhalation of nitrogen oxides fits most closely with the clinical picture and occupational hygiene measurements, and seems the likeliest cause of the syndrome observed. We have named this "cold blast furnace syndrome". To date, all workers have made a full recovery, but the long term consequences of "cold blast furnace syndrome" are difficult to predict. In the literature, acute inhalational exposures to $\mathrm{NO}_{\mathrm{x}}$ have been associated with the development of reactive airways dysfunction syndrome (RADS), irritant induced asthma, pulmonary fibrosis, and obliterative bronchiolitis.

Table 1 Clinical findings on attendance at hospital

\begin{tabular}{|c|c|c|c|}
\hline Patient characteristics & 1 & 2 & 3 \\
\hline Smoker & + & + & + \\
\hline Past respiratory disease & None & None & Asthma \\
\hline \multicolumn{4}{|l|}{ Symptoms } \\
\hline Breathlessness & + & ++ & ++ \\
\hline Chest tightness & + & ++ & ++ \\
\hline Headache & + & + & + \\
\hline Haemoptysis & - & + & - \\
\hline Rigors & + & + & + \\
\hline Nausea & - & - & + \\
\hline Wheeze & - & - & - \\
\hline \multicolumn{4}{|l|}{ Investigations } \\
\hline Temperature ( $\left.{ }^{\circ} \mathrm{C}\right)$ & 38.9 & 38.4 & 38.7 \\
\hline Pulse (beats/minute) & 140 & 110 & 100 \\
\hline $\begin{array}{l}\% \mathrm{O}_{2} \text { saturation (on high flow } \\
\text { oxygen) }\end{array}$ & 91 & 94 & 92 \\
\hline MetHb\% & 0.6 & 0.5 & 0.9 \\
\hline Exhaled CO (parts per million) & 1.4 & 1.6 & 1.2 \\
\hline White cell count & 21.6 & 18.4 & 12.7 \\
\hline Liver function tests & Normal & Not done & $\begin{array}{l}\text { Increased } \\
\gamma G T\end{array}$ \\
\hline $\mathrm{FEV}_{1}$ (I) (\%pred) & $3.89(89)$ & $1.51(40)$ & $2.25(51)$ \\
\hline FVC (I) (pred) & $5.45(105)$ & $1.77(39)$ & $2.52(48)$ \\
\hline Chest $x$ ray infiltrates & + & ++ & ++ \\
\hline
\end{tabular}


"Cold blast furnace syndrome" is a potential hazard during the manufacture of steel even using the most modern of processes, and should be considered in the differential diagnosis of acute toxic inhalational injuries in blast furnace workers.

\section{ACKNOWLEDGEMENTS}

We thank Dr Chris Darling, occupational physician, and the blast furnace operators for their helpful assistance in investigation of the problem and development of suitable solutions.

\section{Authors' affiliations}

I Tague, K Burton, R Buchan, Occupational Health Services, Bluescope Steel, Port Kembla, NSW 2500, Australia

P Llewellin, Illawarra Regional Hospital, Wollongong, NSW 2500,

Australia

D H Yates, Dust Diseases Board (DDB) Research \& Education Unit and St Vincent's Hospital, Sydney, NSW 2010, Australia

Correspondence to: Dr D H Yates, Dept of Thoracic Medicine, Xavier 4, St Vincent's Hospital, Darlinghurst, Sydney, NSW 2010, Australia;

Deborahy88@hotmail.com

Accepted 2 November 2003

\section{REFERENCES}

1 National Occupational Health and Safety Commission. Worksafe Australia exposure standards for atmospheric contaminants, 3rd edn. Canberra: Australian Government Publishing Service, May 1995.

2 Blekkenhorst F, Brandenburg JH, Stolwijk CSM. Stress corrosion cracking in hot blast stoves at Hoogovens ljmuiden. Iron and Steel Engineer 1980;57:55-9.

3 Lobemeier F, Robusch G, Cronert W. Experience gained in stress corrosion cracking on hot blast stoves. Iron and Steel Engineer 1980;57:48-52.

4 Lowry T, Schuman LM. "Silo-filler's disease" - a syndrome caused by nitrogen dioxide. JAMA 1956;162:153-60.

5 Clutton-Brock J. Two cases of poisoning by contamination of nitrous oxide with higher oxides of nitrogen during anaesthesia. $\mathrm{Br} J$ Anaesth 1967;39:388-92

6 Hedberg K, Hedberg CW, Iber C, et al. An outbreak of nitrogen dioxideinduced respiratory illness among ice hockey players. JAMA 1989;262:3014-17.

7 NIOSH. Recommended standard for occupational exposure to oxides of nitrogen. NIOSH, 1976:657-645/24.

8 Morrow PE. Toxicological data on NOx: an overview. J Toxicol Environ Health 1984; 13:205-27.

9 Austin AT. The chemistry of the higher oxides of nitrogen as related to the manufacture, storage and administration of nitrous oxide. $\mathrm{Br} J$ Anaesth 1967;39:345-50

10 Finer NN, Etches PC, Kamstra B, et al. Inhaled nitric oxide in infants referred for extracorporeal membrane oxygenation: dose response. J Pediatr 1994; 124:302-8. 